Check for updates

Cite this: RSC Adv., 2017, 7, 28655

\title{
A novel impedimetric aptasensor based on AuNPs- carboxylic porous carbon for the ultrasensitive detection of ochratoxin A
}

\begin{abstract}
Min Wei (iD * and Wenyang Zhang
A novel aptasensor based on AuNPs-carboxylic porous carbon (cPC) is developed for the ultrasensitive detection of ochratoxin A (OTA) via electrochemical impedance spectroscopy. The prepared AuNPsCPC, which combines the porous structure of CPC with the good conductivity of AuNPs, is used as an excellent carrier for the immobilization of capture DNA (cDNA), which enhances the loading of the aptamer and amplifies the impedimetric signal. When the target OTA is present, due to the complex effect of the three-dimensional macroporous structure of the AuNPs-cPC on the immobilization of CDNA, hybridization between the aptamer and CDNA and the conformational change of the OTAaptamer, the OTA-aptamer complex may not be released from the electrode surface, which leads to an increase in the $R_{\mathrm{ct}}$ signal. Through optimization of the important parameters, the optimal aptamer concentration of $10 \mu \mathrm{mol} \mathrm{L}-1$ and optimal incubation time of $9 \mathrm{~min}$ are obtained. Under the optimal conditions, the $\Delta R_{\mathrm{ct}}$ is linearly proportional to OTA concentration in a logarithmic way in the range of 1 $\times 10^{-8}$ to $0.1 \mathrm{ng} \mathrm{mL}^{-1}$, and the actual limit of detection is $1 \times 10^{-8} \mathrm{ng} \mathrm{mL}^{-1}$.
\end{abstract}

Received 13th April 2017

Accepted 13th May 2017

DOI: $10.1039 / c 7 r a 04209 d$

rsc.li/rsc-advances
Moreover, there are some issues with the stability or modification of antibodies. ${ }^{\mathbf{1 0}}$ Compared with antibodies, aptamers have vital advantages such as high specificity and affinity, good stability, easy modification, simple production and significant chemical simplicity. ${ }^{\mathbf{1 1 - 1 3}}$ Thus, they offer a powerful alternative to antibodies as biological recognition molecules and have been developed for different aptasensors to detect OTA. ${ }^{\mathbf{1 4 - 2 0}}$

For the fabrication of electrochemical aptasensors, the immobilization of biomolecules is crucial. Due to their superior properties, various carbon materials such as carbon nanotubes and graphene have been used as carriers for the effective fabrication of OTA aptasensors. ${ }^{21,22}$ Owing to its high specific surface area, large pore volume, good electronic conductivity, well controlled pore size and surface properties, porous carbon has been successfully used to immobilize biomolecules for biosensors $^{23}$ and is suitable for the design of improved electrochemical aptasensors. On the other hand, in view of their unique physicochemical properties such as good biocompatibility, active surface, catalytic properties and excellent conductivity, AuNPs have been combined with other nanomaterials to boost the performance of aptasensors including improving loading capacity, retaining the activity of biomolecules, and enhancing response sensitivity. ${ }^{24,25}$

In this work, a novel aptasensor based on AuNPs-carboxylic porous carbon (cPC) is developed for the ultrasensitive detection of OTA by electrochemical impedance spectroscopy. The combined porous structure of cPC with good conductivity of AuNPs results in AuNPs-cPC being an excellent carrier for the immobilization of abundant of capture DNA, which enhances 
the loading of aptamer and offers a significant impedimetric amplification strategy for the detection of OTA.

\section{Experimental}

\section{Materials and chemicals}

All oligonucleotides were synthesized by Sangong Biotech (Shanghai, China) Co., Ltd., and their base sequences were: capture DNA (cDNA): 5'-HS-TGT CCG ATG CTC; and OTA aptamer (apt): 5'-GAT CGG GTG TGGGTG GCG TAA AGG GAG CAT CGG ACA-3' $50 \mathrm{mM}, \mathrm{pH} 7.4$ Tris- $\mathrm{HCl}$ was prepared using $0.2 \mathrm{M} \mathrm{NaCl}$ and $1.0 \mathrm{mM}$ EDTA and the $\mathrm{pH}$ adjusted with $0.1 \mathrm{M}$ $\mathrm{HCl}$. All other chemicals were of analytical reagent grade.

\section{Apparatus}

All electrochemical experiments were performed on a CHI 660E electrochemical workstation (Shanghai Chenhua Instrument Corporation, China) using a three-electrode system comprised of a glassy carbon electrode (GCE) as the working electrode, platinum wire as the auxiliary electrode, and $\mathrm{Ag} / \mathrm{AgCl}$ as the reference electrode. Scanning electron microscopy (SEM) was performed using a JEOL JSM7100F SEM (JEOL, Japan). Transmission electron microscopy (TEM) was performed using a JEOL JEM-100SX TEM (JEOL, Japan).

\section{Preparation of apt/AuNPs-cPC-cDNA/GCE sensor}

Scheme 1 illustrates the process for the fabrication of the apt/ AuNPs-cPC-cDNA/GCE sensor and its application for OTA detection.

The GCE was carboxylated via scanning cyclic voltammetry (CV) with $0.5 \mathrm{M} \mathrm{H}_{2} \mathrm{SO}_{4}$. Using a mixture solution of EDC $(40 \mu \mathrm{L}$, $0.1 \mathrm{M})$ and NHS $(40 \mu \mathrm{L}, 0.1 \mathrm{M})$ as the crosslinking agent, the carboxylated GCE was immersed in $\mathrm{NH}_{2}\left(\mathrm{CH}_{2}\right)_{2} \mathrm{SH}(80 \mu \mathrm{L}, 0.1 \mathrm{M})$ solution and incubated to obtain the -SH/GCE.

Honeycomb-like porous carbon was prepared according to our previous report, ${ }^{23}$ and then carboxylated using $\mathrm{H}_{2} \mathrm{SO}_{4}$ and $\mathrm{HNO}_{3}$ to obtain carboxylic porous carbon (cPC). $12 \mathrm{mg}$ of the prepared cPC was firstly activated with $40 \mathrm{mg}$ of EDC and $70 \mathrm{mg}$ of NHS in $8 \mathrm{~mL}$ of ethanol $(95 \%, \mathrm{v} / \mathrm{v})$ and the mixture was stirred for $8 \mathrm{~h}$ at room temperature. Then, $50 \mathrm{mg}$ of $\mathrm{NH}_{2}\left(\mathrm{CH}_{2}\right)_{2} \mathrm{SH}$ was added to the mixture and the solution was stirred for $12 \mathrm{~h}$ at room temperature. Next, the mixture was centrifuged at $12000 \mathrm{rpm}$ for $15 \mathrm{~min}$ and washed repeatedly with ethanol to remove the excess $\mathrm{NH}_{2}\left(\mathrm{CH}_{2}\right)_{2}$ $\mathrm{SH}$, and then dried under vacuum to obtain the $-\mathrm{SH}$ modified $\mathrm{cPC}$.

The $-\mathrm{SH}$ modified $\mathrm{cPC}$ was dispersed in $20 \mathrm{~mL}$ pure water. $600 \mu \mathrm{L}$ of $\mathrm{HAuCl}_{4}(1 \mathrm{wt} \%)$ and $200 \mu \mathrm{L}$ of $0.2 \mathrm{M} \mathrm{K}_{2} \mathrm{CO}_{3}$ was rapidly added under stirring, and then $400 \mu \mathrm{L}$ of freshly prepared $\mathrm{NaBH}_{4}\left(0.5 \mathrm{mg} \mathrm{mL}{ }^{-1}\right)$ was quickly added to the mixture by repeating 4 times. Next, the mixture was sequentially stirred for $5 \mathrm{~min}$, and AuNPs with an average diameter of $50 \mathrm{~nm}$ were

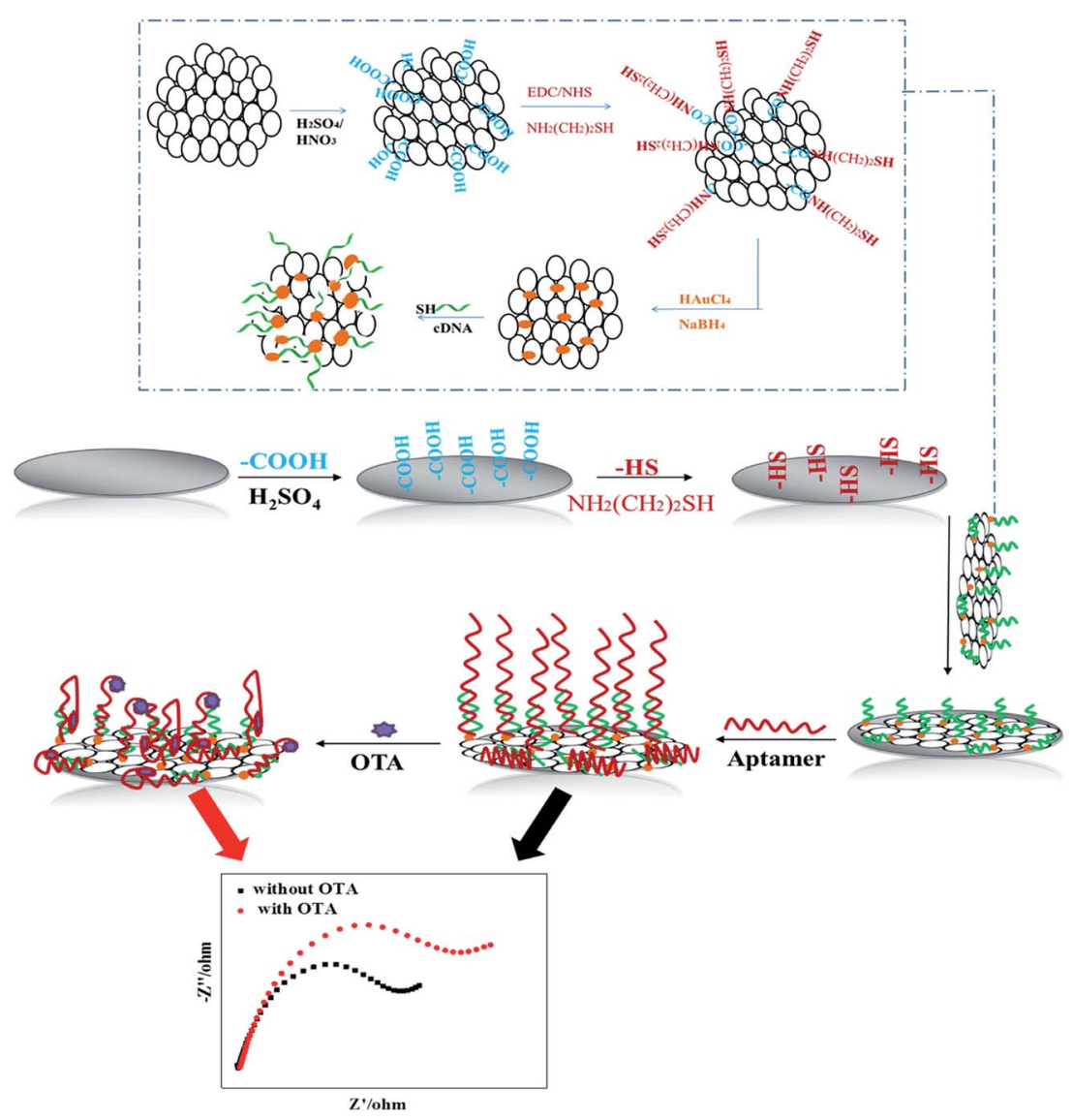

Scheme 1 Schematic illustration of fabrication of the apt/AuNPs-cPC-cDNA/GCE sensor and its application for OTA detection. 
obtained on the surface of cPC (AuNPs-cPC). Finally, the AuNPs-cPC was centrifuged at $10000 \mathrm{rpm}$ and washed with pure water, and then dispersed in $10 \mathrm{~mL}$ pure water by ultrasound.

cDNA $(45 \mu \mathrm{L}, 100 \mu \mathrm{M})$ was added to $500 \mu \mathrm{L}$ of AuNPs-cPC suspension and incubated overnight. Next, the solution was incubated with $\mathrm{NaCl}(50 \mu \mathrm{L}, 2 \mathrm{M})$ for $24 \mathrm{~h}$ and centrifuged at $13000 \mathrm{rpm}$ to remove the unbound cDNA. The precipitate was repeatedly rinsed and redispersed in $5 \mathrm{~mL}$ Tris- $\mathrm{HCl}$ solution to obtain AuNPs-cPC-cDNA. $5 \mu \mathrm{L}$ of AuNPs-cPC-cDNA was immobilized on the surface of the $-\mathrm{SH} / \mathrm{GCE}$ electrode via $\mathrm{S}-\mathrm{Au}$ bonds. Then, $2 \mathrm{wt} \%$ BSA was used to block the excessive active groups. Subsequently, $5 \mu \mathrm{L}$ of $5 \mu \mathrm{M}$ aptamer solution was dropped on the AuNPs-cPC-cDNA/GCE surface and the hybridization reaction was allowed to proceed for a certain time at $37{ }^{\circ} \mathrm{C}$ to obtain the apt/AuNPs-cPC-cDNA/GCE sensor. After the hybridization reaction, the prepared sensor was rinsed with $\mathrm{pH}$ 7.4 Tris- $\mathrm{HCl}$ several times to remove unbound aptamer.

\section{Results and discussion}

\section{Characterization of the prepared AuNPs-cPC-cDNA}

The morphology of materials was characterized via SEM and TEM, and the results are shown in Fig. 1. Fig. 1A shows that cPC has a vast three-dimensional interconnected porous structure with the average pore diameter of about $700 \mathrm{~nm}$. As shown in Fig. 1B, a large number of AuNPs with the average diameter of $50 \mathrm{~nm}$ were irregularly dispersed in various parts of the cPC, which indicates that AuNPs were successfully loaded into cPC. The TEM image of AuNPs-cPC (Fig. 1C) shows the agglomeration of particles on the
cPC supports, which indicates that the AuNPs were successfully adhered to the exterior and the interior of cPC. Fig. 1D shows a thick coating the AuNPs-cPC composite, which indicates that cDNA was successfully immobilized on the AuNPs-cPC composite.

\section{Electrochemical characterization of apt/AuNPs-cPC-cDNA/ GCE sensor}

Electrochemical impedance spectroscopy was used to characterize the apt/AuNPs-cPC-cDNA/GCE sensor. As shown in Fig. 2, for the bare GCE (a), the redox probe $\left[\mathrm{Fe}(\mathrm{CN})_{6}\right]^{3-/ 4-}$ easily reached the electrode surface, and the charge transfer resistance $\left(R_{\mathrm{ct}}\right)$ was $144 \mathrm{ohm}$, which indicates that the treated bare electrode had good conductivity. For the AuNPs-cPC-cDNA/ GCE (b), although the existence of AuNPs-cPC could promote electron transfer and increase binding sites for cDNA, the negatively charged phosphate backbones of the immobilized cDNA prevented $\left[\mathrm{Fe}(\mathrm{CN})_{6}\right]^{3-/ 4-}$ from reaching the electrode surface. Therefore, the synergistic effect of cDNA and AuNPscPC resulted in the $R_{\mathrm{ct}}$ of the AuNPs-cPC-cDNA/GCE increasing to $530 \mathrm{ohm}$. After the aptamer hybridized with cDNA, the negative charge density of the electrode surface increased, which led to greater repulsion between the electrode surface and $\left[\mathrm{Fe}(\mathrm{CN})_{6}\right]^{3-/ 4-}$, thus the $R_{\text {ct }}$ of the apt/AuNPs-cPC-cDNA/ GCE sensor (c) significantly increased to $1373 \mathrm{ohm}$.

\section{The detection mechanism of OTA based on the apt/AuNPs-} cPC-cDNA/GCE sensor

Fig. 3 shows the EIS spectra of the apt/AuNPs-cPC-cDNA/GCE sensor before (a) and after (b) incubation with OTA. It can be
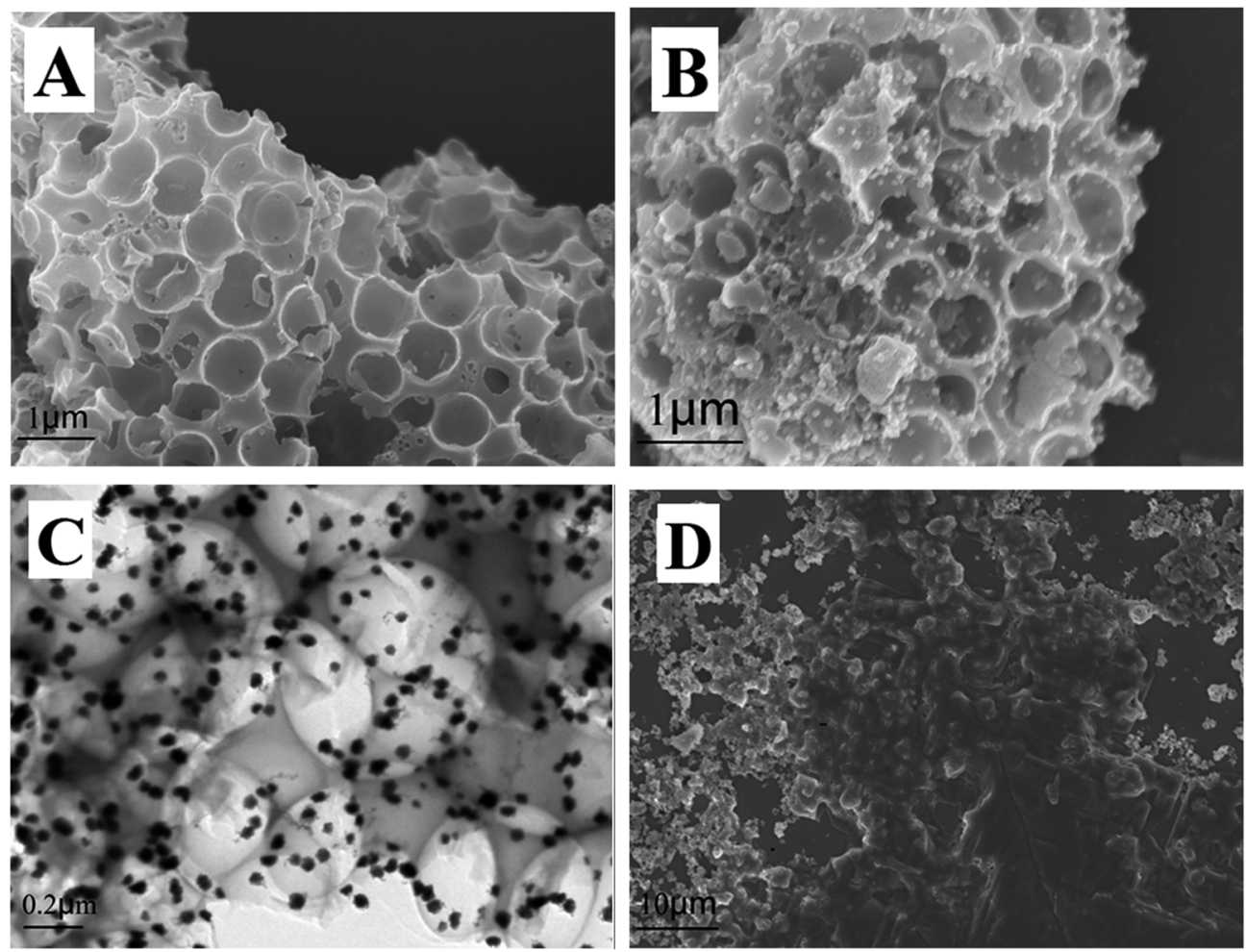

Fig. 1 (A) SEM image of CPC, (B) SEM image and (C) TEM image of AuNPs-cPC and (D) SEM image of AuNPs-cPC-cDNA. 


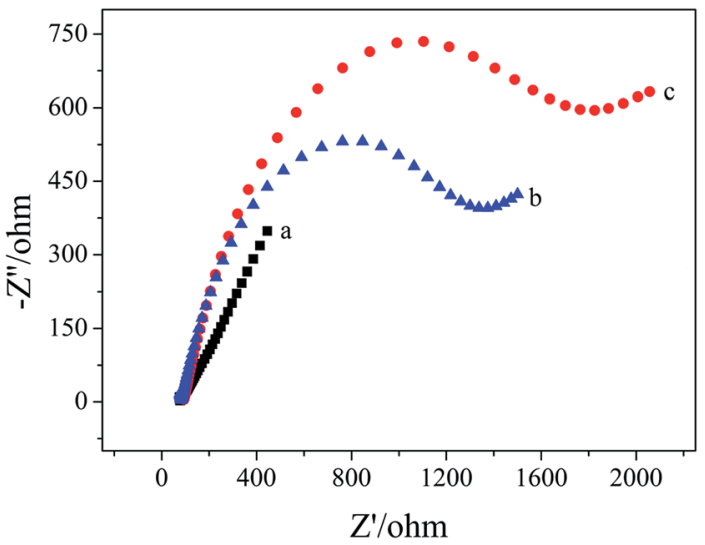

Fig. 2 EIS of $10.00 \mathrm{mM}\left[\mathrm{Fe}(\mathrm{CN})_{6}\right]^{3-/ 4-}$ containing $0.1 \mathrm{M} \mathrm{KCl}$ on the different electrodes. (a) GCE, (b) AuNPs-cPC-cDNA/GCE and (c) apt/ AuNPs-cPC-cDNA/GCE.

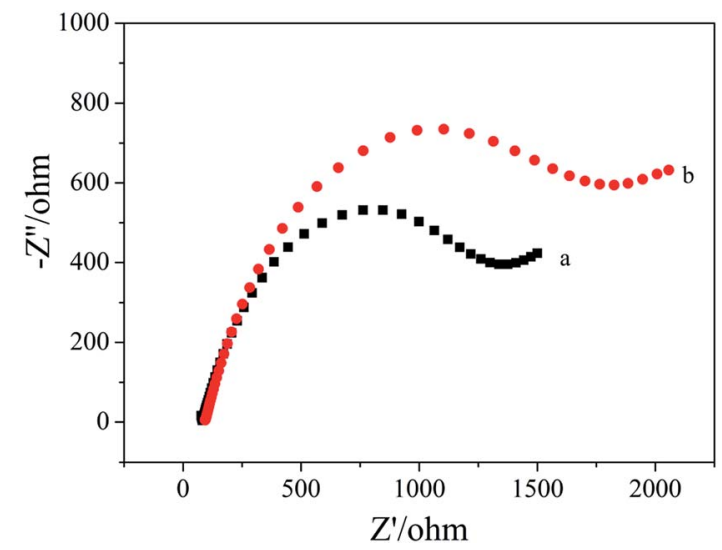

Fig. 3 EIS of $10.00 \mathrm{mM}\left[\mathrm{Fe}(\mathrm{CN})_{6}\right]^{3-/ 4-}$ containing $0.1 \mathrm{M} \mathrm{KCl}$ on the apt/ AuNPs-cPC-cDNA/GCE sensor. (a) $0 \mathrm{ng} \mathrm{mL}^{-1}$ OTA and (b) $1 \times 10^{-8}$ ng $\mathrm{mL}^{-1}$ OTA.

seen that $R_{\mathrm{ct}}$ increased from $1373 \mathrm{ohm}$ to $1852 \mathrm{ohm}$ when the apt/ AuNPs-cPC-cDNA/GCE sensor was incubated with $1 \times 10^{-8} \mathrm{ng}$ $\mathrm{mL}^{-1}$ OTA for $9 \mathrm{~min}$. We speculate that the increase in $R_{\mathrm{ct}}$ after OTA incubation is not only the result of the repulsion between the electrode surface and the negatively charged redox couple induced by the negatively charged OTA at $\mathrm{pH} 7.4,{ }^{26,27}$ but also due to the complex effect of the aptasensor which is as follows: when OTA combines with the aptamer, the formation of the OTAaptamer complex results in a conformational change in the aptamer. However, the existence of the three-dimensional macroporous structure of AuNPs-cPC has a complex effect on the immobilization of the cDNA, the hybridization between aptamer and cDNA, and the conformational change of OTA-aptamer, which results in the OTA-aptamer complex not being released from the electrode surface and an increase in the $R_{\text {ct }}$ signal. Relevant literature also confirms that the involvement of nanomaterials or other substances could affect the detection principle. For example, Wu et al. ${ }^{28}$ immobilized an aptamer on the electrode surface via $\mathrm{Au}-\mathrm{S}$ bonds, and the resistance of the electrode surface increased in the presence of OTA due to the conformational

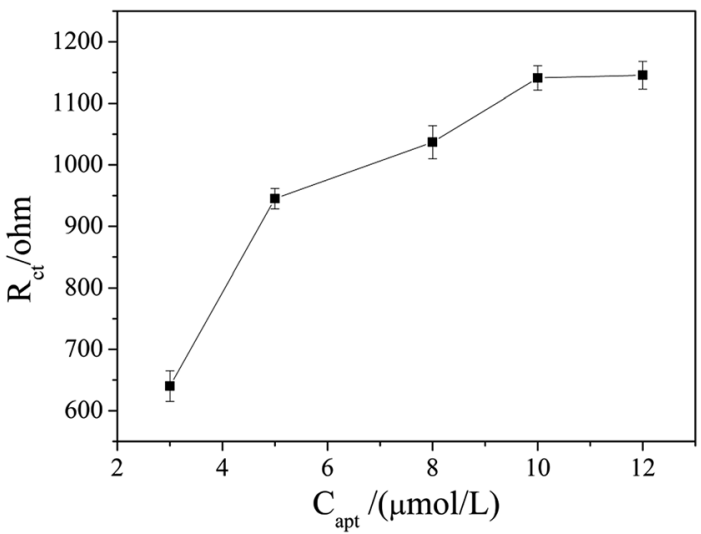

Fig. 4 Effect of aptamer concentration on the EIS responses of the apt/AuNPs-cPC-cDNA/GCE sensor.

change in the aptamer-OTA complex. On the contrary, Prabhakar et $a l .{ }^{29}$ deposited an LB film (PANI-SA) on the electrode surface to immobilize an aptamer. When OTA was added, the PANI chains acted as electron-conducting molecules to accelerate electron transfer and decrease the resistance. Prieto-Simón et al. ${ }^{30}$ developed a "signal off" aptasensor based on the hybridization between aptamer-ALP and the complementary strand which immobilized on the electrode surface to detect OTA, and surface plasmon resonance assays confirmed the conformational switch of the aptamer rather than aptamer displacement by dehybridization from the DNA-modified sensor surface in the presence of OTA, which increased $R_{\mathrm{ct}}$. In our experiment, the involvement of the three-dimensional macroporous structure of AuNPs-cPC affected the conformational switch of the OTA-aptamer complex rather than releasing it from the electrode surface in the presence of OTA, which is a significant impedimetric amplification strategy for OTA detection.

\section{Optimization of the experimental conditions}

The aptamer concentration could affect the loading of aptamer on the electrode surface and the conformational changes of the aptamer in the reaction system, and thus affect the sensitivity and accuracy of the sensor. As shown in Fig. 4 , the $R_{\text {ct }}$ increased dramatically when the aptamer concentration increased from 3 $\mu \mathrm{mol} \mathrm{L}^{-1}$ to $5 \mu \mathrm{mol} \mathrm{L}^{-1}$, and then increased slowly with further increase the aptamer concentration. When the aptamer concentration increased to $10 \mu \mathrm{mol} \mathrm{L}^{-1}, R_{\mathrm{ct}}$ tended to be stable, which indicates that the amount of aptamer on the electrode surface reached saturation. Therefore, $10 \mu \mathrm{mol} \mathrm{L}^{-1}$ was selected as the optimal aptamer concentration.

The OTA incubation time not only affects the conformational change in the aptamer-OTA complex, but also is one of the important indicators that directly measure whether the aptamer sensor is suitable for practical application. As shown in Fig. 5, the $R_{\mathrm{ct}}$ of the sensor obviously increased in the early stage with an increase in incubation time up to $9 \mathrm{~min}$, where the $R_{\mathrm{ct}}$ of $2089 \mathrm{ohm}$ was obtained. Beyond that, the $R_{\mathrm{ct}}$ did not exhibit further increase and basically reached a plateau. Consequently, 9 min was adopted as the optimum incubation time and employed for all other investigations. 


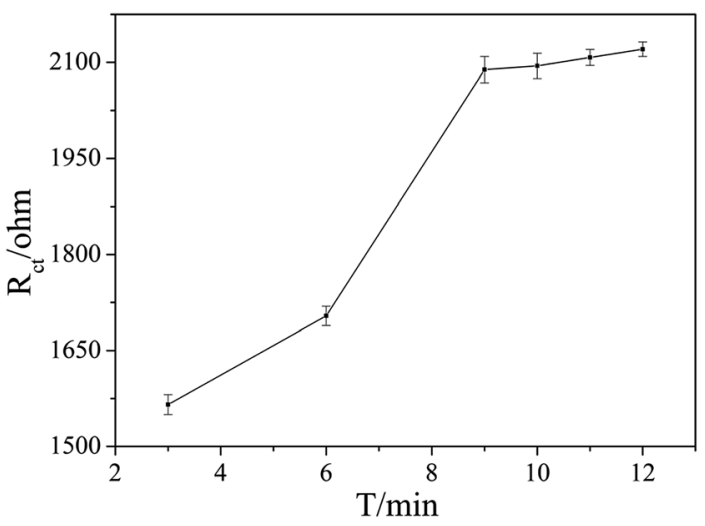

Fig. 5 Effect of the different binding times of OTA with the aptamer on the EIS responses. The OTA concentration was $1 \times 10^{-7} \mathrm{ng} \mathrm{mL}^{-1}$.

\section{Analytical performance of the apt/AuNPs-cPC-cDNA/GCE sensor for impedimetric detection of OTA}

Under the optimized conditions, the fabricated aptasensor was adopted for the impedimetric detection of OTA at different concentrations. It was found that the $\Delta R_{\mathrm{ct}}$ increased as the OTA concentration increased in a wide range of $1 \times 10^{-8}$ to $1000 \mathrm{ng}$ $\mathrm{mL}^{-1}$ (Fig. 6A). As shown in Fig. 6B, $\Delta R_{\mathrm{ct}}$ was linearly proportional to OTA concentration in a logarithmic way in the range of $1 \times 10^{-8}$ to $0.1 \mathrm{ng} \mathrm{mL}{ }^{-1}$, and the linear regression equation was
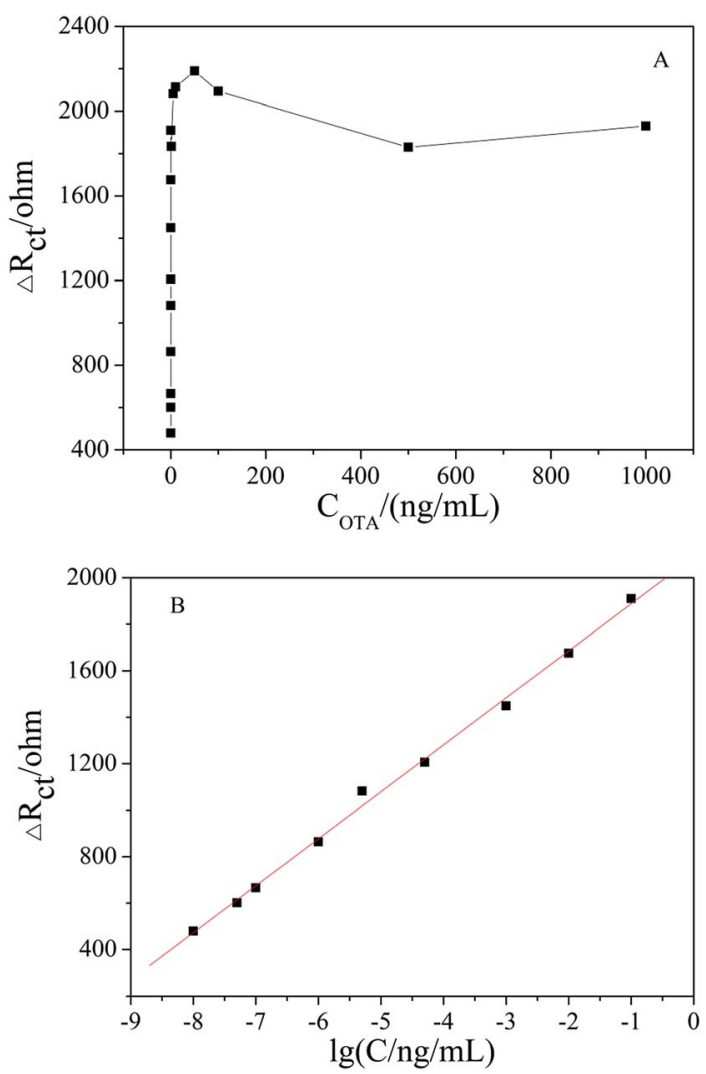

Fig. 6 (A) EIS of apt/AuNPs-cPC-cDNA/GCE with OTA concentration in the range of $1 \times 10^{-8}$ to $1000 \mathrm{ng} \mathrm{mL}^{-1}$. (B) Linear relationship curve between $\Delta R_{\mathrm{ct}}$ and $\lg [\mathrm{OTA}]$.
Table 1 Comparison with other reported aptasensors for OTA detection

\begin{tabular}{llll}
\hline $\begin{array}{l}\text { Amplified signal } \\
\text { method }\end{array}$ & $\begin{array}{l}\text { Linear range } \\
\left(\mathrm{ng} \mathrm{mL} \mathrm{mL}^{-1}\right)\end{array}$ & $\begin{array}{l}\text { Detection limit } \\
\left(\mathrm{ng} \mathrm{mL} \mathrm{m}^{-1}\right)\end{array}$ & Reference \\
\hline AuNPs-MB & $0.1-20$ & 0.03 & 31 \\
AuNPs-MB & $1 \times 10^{-4}$ to 1 & $9.5 \times 10^{-5}$ & 28 \\
AuNPs-rGO & $1 \times 10^{-3}$ to 50 & $3.0 \times 10^{-4}$ & 32 \\
AuNPs-rGO & $0.1-200$ & 0.03 & 25 \\
RT-qPCR & $5 \times 10^{-6}$ to 5 & $1.0 \times 10^{-6}$ & 33 \\
RCA & - & $6.5 \times 10^{-5}$ & 34 \\
AuNPs-cPC & $1 \times 10^{-8}$ to 0.1 & $1 \times 10^{-8}$ & This work
\end{tabular}

$\Delta R_{\mathrm{ct}}(\Omega)=202.23 \lg [\mathrm{OTA}]\left(\mathrm{ng} \mathrm{mL} \mathrm{m}^{-1}\right)+2090.17\left(R^{2}=0.996\right)$. The actual detection limit was $1.0 \times 10^{-8} \mathrm{ng} \mathrm{mL}{ }^{-1}$. A comparison of the results obtained with the reported literature is presented in Table 1, which shows that the apt/AuNPs-cPC-cDNA/GCE sensor is superior.

\section{Reproducibility and repeatability of the apt/AuNPs-cPC- cDNA/GCE sensor}

The reproducibility of the developed apt/AuNPs-cPC-cDNA/GCE sensor was evaluated with inter-assay precision. Five apt/AuNPscPC-cDNA/GCE sensors were tested via EIS with same OTA concentration under the same experimental conditions. A relative standard deviation (RSD) of $5.62 \%$ was calculated, which indicates the good reproducibility of the developed aptasensor. The intra-assay precision of the apt/AuNPs-cPC-cDNA/GCE sensor was evaluated by six repetitive measurements with one electrode and an RSD of $4.53 \%$ was obtained, which indicates that the prepared aptasensor has acceptable repeatability.

\section{Specificity of the apt/AuNPs-cPC-cDNA/GCE sensor}

To investigate the specificity of the apt/AuNPs-cPC-cDNA/GCE sensor toward OTA, the system was employed for the analysis of $0.1 \mathrm{ng} \mathrm{mL} \mathrm{m}^{-1}$ AFB1. As shown in Fig. 7, the EIS response from AFB1 showed no obvious variation in comparison with that of the control test, whereas an obvious increase in the EIS response was

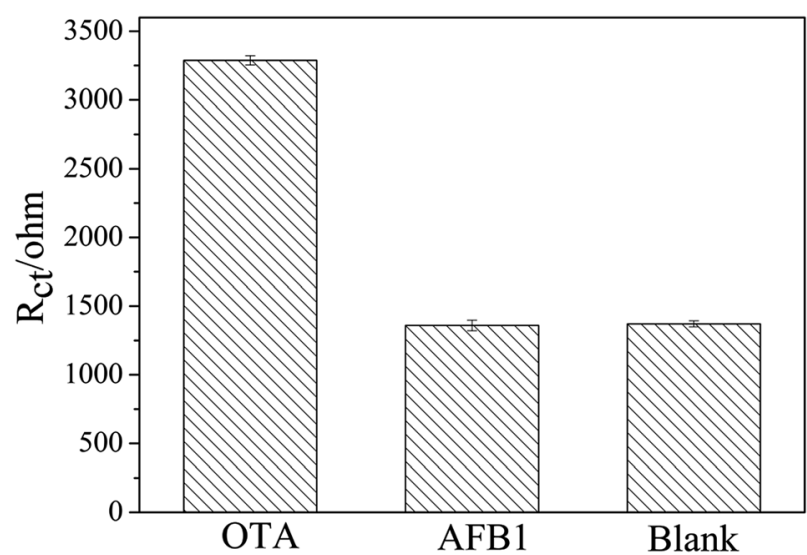

Fig. 7 Specificity evaluation of the proposed aptasensor for $0.1 \mathrm{ng}$ $\mathrm{mL}^{-1}$ OTA against $0.1 \mathrm{ng} \mathrm{mL}^{-1}$ AFB1. 
Table 2 Detection of OTA in soybean samples

\begin{tabular}{lllll}
\hline Sample & $\begin{array}{l}\text { Added } \\
\left(\mathrm{ng} \mathrm{mL}^{-1}\right)\end{array}$ & $\begin{array}{l}\text { Measured } \\
\left(\mathrm{ng} \mathrm{mL}^{-1}\right)\end{array}$ & Recovery\% & $\begin{array}{l}\text { Average } \\
\text { recovery\% }\end{array}$ \\
\hline 1 & $1 \times 10^{-6}$ & $1.02 \times 10^{-6}$ & 102 & 101.67 \\
2 & & $1.08 \times 10^{-6}$ & 108 & \\
3 & & $0.95 \times 10^{-6}$ & 95 &
\end{tabular}

observed for $0.1 \mathrm{ng} \mathrm{mL}^{-1}$ OTA. This result suggests that the proposed aptasensor is specific for OTA detection.

\section{Analytical application in real sample}

To investigate the practical application of the developed aptasensor, the detection of OTA in a soybean sample was performed. As shown in Table 2, the recoveries of the spiked samples ranged from $95 \%$ to $108 \%$ with the average recovery of $101.67 \%$, which implies that the as-prepared aptasensor can be used for OTA detection in real samples with the satisfactory results.

\section{Conclusions}

In this work, a signal-amplified impedimetric aptasensor based on AuNPs-cPC has been successfully developed for the ultrasensitive detection of OTA. Due to the advantages of the threedimensional macroporous structure and good conductivity of AuNPs-cPC, the prepared apt/AuNPs-cPC-cDNA/GCE sensor could enhance the loading of the aptamer and amplify the $R_{\mathrm{ct}}$ signal. Under optimal conditions, the developed aptasensor achieved an extraordinary detection limit of $1 \times 10^{-8} \mathrm{ng} \mathrm{mL} \mathrm{m}^{-1}$, which is better than other reported aptasensors for OTA detection. This signal-amplified impedimetric aptasensor may provide a powerful tool for the detection of OTA and other hazards for food safety.

\section{Acknowledgements}

This research was supported by the Fundamental Research Funds for the Henan Provincial Colleges and Universities in Henan University of Technology (2016RCJH04).

\section{References}

1 A. L. Sun, Y. F. Zhang, G. P. Sun, X. N. Wang and D. P. Tang, Biosens. Bioelectron., 2017, 89, 659-665.

2 J. Tang, Y. P. Huang, C. C. Zhang, H. Q. Liu and D. P. Tang, Biosens. Bioelectron., 2016, 86, 386-392.

3 T. H. Ha, Toxins, 2015, 7, 5276-5300.

4 M. A. Andrade and F. M. Lanças, J. Chromatogr. A, 2017, 1493, 41-48.

5 W. Zhu, C. Ren, Y. Nie and Y. Xu, Food Control, 2016, 64, 3744.

6 Y. Chen, M. Yang, Y. Xiang, R. Yuan and Y. Chai, Nanoscale, 2014, 6, 1099-1104.

7 D. B. Hernández, R. K. Mishra, R. Muñoz and J.-L. Marty, Sens. Actuators, B, 2017, 246, 606-614.
8 L. Lv, D. Li, R. Liu, C. Cui and Z. Guo, Sens. Actuators, B, 2017, 246, 647-652.

9 K.-J. Huang, H.-L. Shuai and Y.-X. Chen, Sens. Actuators, B, 2016, 225, 391-397.

10 K. S. Schmidt, S. Borkowski, J. Kurreck, A. W. Stephens, R. Bald, M. Hecht, M. Friebe, L. Dinkelborg and V. A. Erdmann, Nucleic Acids Res., 2004, 32, 5757-5765.

11 S. Dai, S. Wu, N. Duan, J. Chen, Z. Zheng and Z. Wang, Biosens. Bioelectron., 2017, 91, 538-544.

12 A. Rhouati, C. Yang, A. Hayat and J. L. Marty, Toxins, 2013, 5, 1988-2008.

13 C. Wang, J. Qian, K. Wang, X. Yang, Q. Liu, N. Hao, C. Wang, X. Dong and X. Y. Huang, Biosens. Bioelectron., 2016, 77, 1183-1191.

14 C. Q. Wang, J. Qian, K. Wang, K. Wang, Q. Liu, X. Dong, C. K. Wang and X. Y. Huang, Biosens. Bioelectron., 2015, 68, 783-790.

15 X. W. Yang, J. Qian, L. Jiang, Y. Yan, K. Wang, Q. Liu and K. Wang, Bioelectrochemistry, 2014, 96, 7-13.

16 L. Yang, Y. Zhang, R. Li, C. Lin, L. Guo and B. Qiu, Biosens. Bioelectron., 2015, 70, 268-274.

17 R. K. Mishra, A. Hayat, G. Catanante, C. Ocana and J.-L. Marty, Anal. Chim. Acta, 2015, 889, 106-112.

18 G. Catanante, R. K. Mishra, A. Hayat and J.-L. Marty, Talanta, 2016, 153, 138-144.

19 R. K. Mishra, A. Hayat, G. Catanante, G. Istamboulie and J.-L. Marty, Food Chem., 2016, 192, 799-804.

20 A. Sharma, A. Hayat, R. K. Mishra, G. Catanante, S. Bhand and J.-L. Marty, Toxins, 2015, 7, 3771-3784.

21 L. Sheng, J. Ren, Y. Miao, J. Wang and E. Wang, Biosens. Bioelectron., 2011, 26, 3494-3499.

22 Z. Guo, J. Ren, J. Wang and E. Wang, Talanta, 2011, 85, 25172521.

23 M. Wei and J. Wang, Sens. Actuators, B, 2015, 211, 29-296.

24 N. Hao, L. Jiang, J. Qian and K. Wang, J. Electroanal. Chem., 2016, 781, 332-338.

25 J. Qian, L. Jiang, X. Yang, Y. Yan, H. Mao and K. Wang, Analyst, 2014, 139, 5587-5593.

26 G. Castillo, I. Lamberti, L. Mosiello and T. Hianik, Electroanalysis, 2012, 24, 512-520.

27 L. Rivas, C. C. Mayorga-Martinez, D. Quesada-Gonzalez, A. Zamora-Galvez, A. Escosura-Muñiz and A. Merkoci, Anal. Chem., 2015, 87, 5167-5172.

28 J. Wu, H. Chu, Z. Mei, Y. Deng and F. Xue, Anal. Chim. Acta, 2012, 753, 27-31.

29 N. Prabhakar, Z. Matharu and B. D. Malhotra, Biosens. Bioelectron., 2011, 26, 4006-4011.

30 B. Prieto-Simón and J. Samitier, Anal. Chem., 2014, 86, 14371444.

31 H. Kuang, W. Chen, D. H. Xu, L. G. Xu, Y. Y. Zhu and L. Q. Liu, Biosens. Bioelectron., 2010, 26, 710-716.

32 L. Jiang, J. Qian, X. W. Yang, Y. Yan, Q. Liu and K. Wang, Anal. Chim. Acta, 2014, 806, 128-135.

33 W. Ma, H. H. Yin, L. G. Xu, Z. Xu and H. Kuang, Biosens. Bioelectron., 2013, 42, 545-549.

34 L. Huang, J. J. Wu, L. Zheng, H. Qian, F. Xue and Y. Wu, Anal. Chem., 2013, 85, 10842-10849. 